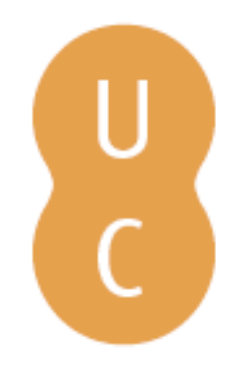

\title{
pompalina
}

\section{André de Resende e a relatinização ortográfica da língua portuguesa}

Autor(es): $\quad$ Pinho, Sebastião Tavares de

Publicado por: Centro de Estudos Clássicos e Humanísticos; Imprensa da Universidade

URL

persistente: URI:http://hdl.handle.net/10316.2/31172

DOI: $\quad$ DOI:http://dx.doi.org/10.14195/978-989-8281-98-2_7

Accessed : $\quad$ 26-Apr-2023 10:35:08

A navegação consulta e descarregamento dos títulos inseridos nas Bibliotecas Digitais UC Digitalis, UC Pombalina e UC Impactum, pressupõem a aceitação plena e sem reservas dos Termos e Condições de Uso destas Bibliotecas Digitais, disponíveis em https://digitalis.uc.pt/pt-pt/termos.

Conforme exposto nos referidos Termos e Condições de Uso, o descarregamento de títulos de acesso restrito requer uma licença válida de autorização devendo o utilizador aceder ao(s) documento(s) a partir de um endereço de IP da instituição detentora da supramencionada licença.

Ao utilizador é apenas permitido o descarregamento para uso pessoal, pelo que o emprego do(s) título(s) descarregado(s) para outro fim, designadamente comercial, carece de autorização do respetivo autor ou editor da obra.

Na medida em que todas as obras da UC Digitalis se encontram protegidas pelo Código do Direito de Autor e Direitos Conexos e demais legislação aplicável, toda a cópia, parcial ou total, deste documento, nos casos em que é legalmente admitida, deverá conter ou fazer-se acompanhar por este aviso.

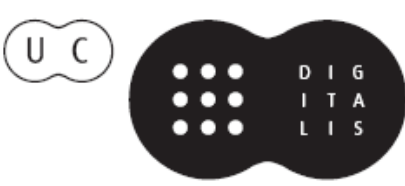


Colecção Autores Gregos e Latinos

SérIe Ensaios

\section{Nair Castro Soares Margarida Miranda Carlota Miranda Urbano}

(Coord.)

HOMO ELOQVENS HOMO POLITICVS

A retórica e a CONSTRUÇÃo da CIDAdE NA IdAdE MÉdia E NO RENASCIMENTO

IMPRENSA DA UNIVERSIDADE DE COIMBRA COIMBRA UNIVERSITY PRESS 


\section{André de REsende e a RELATINIZAÇÃo ortográficA DA LÍngua Portuguesa}

Sebastiāo Tavares de Pinho 
No conhecido movimento de relatinização do português, que teve a sua maior expressão no ambiente renascentista do século XVI, assume incontestável protagonismo o humanista André de Resende, cuja merecida fama não se deve apenas à vasta e variada produção literária escrita em elegante latim, ou por ter sido o inventor da palavra "Lusíadas" e de outro vocabulário épico, como o nome das "Tágides", mas também porque conquistou um justo lugar de relevo entre os principais escritores de língua portuguesa de Quinhentos. ${ }^{1}$

É nessa produção literária em vernáculo que o humanista eborense evidencia a sua declarada propensão para a ortografia latinizante do português, como pretendemos demonstrar com base nos textos de grafia autêntica chegados até nós, a saber:

1 - Carta a D. João de Castro, Lisboa, 16 de Março de 1547 (ANTT, Ms. São Lourenço, IV, fol. 52-53);

2 - Historia da antiguidade da cidade de Evora. Fecta per Meestre Andree de Resende (Évora, 1553 e 1576);

${ }^{1}$ Serafim da Silva Neto emitiu a seu respeito o seguinte juízo: "André de Resende foi exímio e brilhante estilista em língua portuguesa. A sua prosa é das mais vivas e graves do século em que viveu. [...] É serena e corrente, cheia de naturalidade e expressão" (vd. Silva Neto 1947: 84). 
3 - Fala que Meestre Andree de Reesende fez aa Princepsa Domna Ioanna [...] na entrada da ciidade de Evora (incluída na obra anterior deste elenco, fols. $\mathrm{f}$ vij-viij da edição de 1553, e fol. f vj-vij vo da de 1576);

4 - Sermam que pregou ho doctor meestre Andree de Resende [...] en o synodo [...] de Evora [...] ho primeiro domingo do mes de Feuereiro MD LXV (Lisboa, 1565);

5 - Fala que Meestre Andree de Reesende fez a el rey Dom Sebastiam a primeyra vez que entrou en Euora (incluída na obra do no 2 desta lista, Évora, 1576, fols. f viij - $\mathrm{g} \mathrm{v}^{\mathrm{o}}$ );

6 - Ha sancta vida e religiosa conuersaçam de Frey Pedro [...] Scripta per ho doctor Meestre Andree de Reesende (Évora, 1570);

7 - Testamento de André de Resende (Dezembro de 1573).

Todas estas obras foram publicadas pelo autor, com excepçáo evidentemente do seu testamento. Mas, deste, existe publicação póstuma a partir do original, que respeita a primitiva ortografia, conforme esclarece o seu editor (Leitão Ferreira 1916: 130-131) e como podemos comprovar pelo confronto com o sistema ortográfico das restantes obras supracitadas.

Por outro lado, conservou-se o autógrafo da Carta a D. João de Castro, cuja primeira página aqui reproduzo no Anexo I.

Existe também um manuscrito autógrafo do pequeno discurso (da "Fala" que ocupa o terceiro lugar da lista anterior, cuja página inicial vai igualmente 
aqui reproduzida no Anexo II) pronunciado por Resende em finais de Novembro de 1552 e publicado em apêndice à História da cidade de Évora saída a lume em 26 de Outubro de 1553 e em edição póstuma de 1 de Fevereiro de 1576, feita sobre um texto ainda emendado pelo autor, conforme se declara na sua portada: "E agora nesta segunda impressam emendada pelo mesmo autor".

Fica fora deste elenco de pesquisa a Vida do Infante Dom Duarte, escrita em 1567, mas publicada pela primeira vez apenas em 1789, por ordem da Academia das Ciências de Lisboa; em 1842, pela Revista Literária (Porto, vol. IX); e em 1963, nas Obras Portuguesas de Resende, organizadas por José Pereira Tavares. A ortografia, em todas estas ediçóes, foi modernizada e claramente não respeitou a escrita do texto autógrafo, entretanto desaparecido. Por isso não serve aos objectivos deste estudo.

Vejamos o testemunho dos próprios textos resendianos e comecemos por transcrever alguns extractos da primeira Fala, isto é, da pequena oração de entrada pronunciada em finais de Novembro de 1552 perante a princesa Joana de Áustria, filha de Carlos V, aquando da sua entrada em Portugal como noiva do príncipe D. João, filho de D. João III, e no momento em que ela passava pela cidade de Évora. O humanista André de Resende, um dos oradores mais conceituados da época, assume a missão de lhe dar as boas-vindas em nome da capital alentejana e do seu povo, num discurso breve que contém todos os ingredientes oratórios do protesto de 
modéstia pessoal e da exaltação da destinatária, numa grafia sobrecarregada de formas latinizantes ${ }^{2}$ :

Princepsa exclarescida, Princepsa de nos tãto desejada. Se ho immenso \& excessiuo plazer que hoje en nos triumpha, per palauras se podesse explicar, mui pouco seria, ho que hos poetas en has cousas arduas \& difficiles costumauan, desejar cent boccas, \& cent linguas, \& hũa voz aceira $\&$ incansauel. Qua non è tam leue nem tá mediocre ho alegre mouimento de tâtos coraçóes, que per tam poucos instrumentos assi facilmente se lexasse declarar. Mas ja que desta parte ha impossibilidade nos tẽe desengannado, \& de outra, nó padesce ha qualidade do tempo que com longa oraçã detenha V. A. \& impida esta commun alegria, \& acceso desejo de vos veer que nem pode tẽer silencio, nem soffre dilaçam: reduzindo me a ho que breuissima \& summariamente non consente ha razam que lexe de dizer. Princepsa serenissima, esta vossa cijdade [...] en sua origẽe \& fundaçam antiquissima, en ha fee catholica \& religiã christâa entre todas has de Hispania ou mais antigua, ou táto quanto ha que mais, en nobleza de estes regnos ha segunda, \& en lealdade, amor \& seruiço da real coróa delles sen duuida ha primeira, beisa vossas reaes mãos, \& per hũo publico \& gẽeral voto, com os animos chẽos de tanto contentamento, de quanto ho humano intellecto é capaz, pede a d's omnipotente que vossa vinda a estes regnos seja felicissima. Entrae senhora per hos muros dos vossos, $\&$ appousentae vos entre hos vossos, quomo lhes ja entrastes

2 Servimo-nos do texto impresso, que apresenta algumas pequenas variantes da responsabilidade do autor relativamente ao seu manuscrito autógrafo, ainda existente, que ele reviu e aperfeiçoou para efeitos de publicação. Acerca da prioridade de um sobre o outro, vd. Pinho, 2006: 232-238. 
per hos coraçóes, que logo ficaron entreghes [...] (Vd. Fala à Princesa, 1553: fol. vij-vij vo; e fol. viij).

Os vocábulos em itálico apresentam na sua maioria grafias que, por uma ou outra razão, indiciam uma clara preocupação etimológica latina. É o caso da palavra 'Princepsa', que, independentemente da proveniência da sua importação (francesa? ou castelhana?), póe à evidência a forma etimológica latina "princeps" assente no próprio nominativo mediante a simples adjunção do sufixo indicativo do feminino e sem permitir a assimilação da oclusiva -p- por parte da sibilante -s-. É um artifício, ao que parece, da responsabilidade de Resende, mas representa sem dúvida uma motivação etimológica. Isto acontece por quatro vezes nesta "Fala", e vamos encontrá-lo também na Vida de Frei Pedro (fol. a ij - ij vo).

A grafia do vocábulo 'exclarescida" mostra-nos a dupla curiosidade de apresentar, por um lado, o prefixo latino ex-, que deu origem à correspondente forma vernácula es- presente em grande número de vocábulos portugueses desde a Idade Média, e, por outro, o conjunto incoativo -sc-, igualmente herdado do latim, que entrou na formação de verbos de tema em $e$ (-scer), dos quais a maior parte perdeu, desde longa data, o -s-do referido conjunto (dos cerca de 280 verbos dessa formação, apenas perto de 50 conservam hoje a terminação -scer). Resende optou por esta grafia em mais de duas dezenas de formas verbais e mesmo de nomes delas derivados. Só na Vida de Frei Pedro encontramos 
mais de cinquenta passos com os seguintes exemplos: accontescer, admanhescer, cognoscer/cognoscidas, desaparescer, desfallescer / fallescer / fallescido / fallescimento, exvãescer, favorescer, merescer, offerescer, padescer, parescer (mais de vinte cinco vezes), pretenscer, resplandescer.

Outra opção da ortografia resendiana respeita ao uso persistente de consoantes geminadas, de tradição latina, como se vê pelos exemplos colhidos neste texto: o adjectivo 'immenso', que decalca o particípio latino immensus; 'bocca', que assenta directamente no latim bucca, mas que já havia reduzido a geminada na sua forma vernácula do séc. XI, e que o humanista agora adopta; 'desengannado', baseado no latim vulgar ingannare, a partir do latim clássico gannire, (latir, ganir; chilrear, grunhir; cochichar; caramunhar); 'commum', do latim communis; 'acceso', refeito a partir do latim accensus, particípio do verbo accendere, cuja forma portuguesa já havia reduzido a geminada pelo menos no séc. XIV, em que aparecem grafias como 'acesso' e 'acezo'; o advérbio 'summariamente', assente na raiz do substantivo latino summa, que já aparece pelo menos desde os finais do séc. XIV mas com o -m- radical reduzido e cuja geminação ressurge no século de Resende. Bem como as geminadas do vocábulo 'soffre', recebido do verbo latino sufferre $(<$ sub+ferre $)$ através da forma deduzida * sufferere; do substantivo 'intellecto' (do latim intellectus), assumido na língua portuguesa provavelmente antes do séc. XVI, mas que na época de André de Resende já se apresentava correntemente sem geminada, em grafias como 'inteleito' 
ou a moderma 'intelecto'; o imperativo 'appousentae', já detectável desde o séc. XIII sem geminação (apousentar, apoussentar e aposentar) e que Resende grafa com a geminada -pp- em consonância com a etimologia latina $a d+$ pausa, que deu origem a todo o léxico da mesma raiz; e, enfim, a própria formação aglutinada 'delles', que o humanista relaciona naturalmente com o pronome latino ille.

Um caso de latinismo não apenas gráfico mas também morfológico é o do adjectivo 'difficiles', plural modelado na morfologia do correspondente latino difficiles, que passou a ser usado em língua portuguesa no tempo de André de Resende por ele e por outros humanistas amantes da ortografia latinizante. Inclui-se neste caso 'viles', plural de 'vil', e 'horribiles', também usados na Vida de Frei Pedro (fol. a iij vo: "hos officios mais baixos, \& viles"; fol. b: "offerescendolhe visôes horribiles"). À mesma série morfológica pertence, ainda, 'immobile' (ib., fol. a viij). ${ }^{3}$

Em matéria de uso de nasais, como se vê no texto acima transcrito, o antiquário eborense mais uma vez se aproxima da etimologia latina em vocábulos como o advérbio 'non', usado sistematicamente em toda sua obra quer nesta grafia plena que transcreve o latim non, quer na escrita nasalizada 'nô' que se pode presumir corresponder à pronúncia de ambos. $\mathrm{O}$ mesmo se pode

${ }^{3}$ Serafim da Silva Neto cita, a este propósito, mais uma dezena de plurais deste tipo em outros tantos autores contemporâneos de André de Resende, em obras publicadas entre 1553 e 1594 (Silva Neto, 1947: 106). 
dizer do advérbio 'tam', habitualmente escrito à maneira latina; e, ainda, acerca da preposição 'en', em vez de 'em' por ser graficamente mais próxima da original latina in, o que acontece igualmente com a preposiçáo 'sen', que surge em toda a obra portuguesa de Resende e cuja grafia aponta, mais directamente do que a sua alternante 'sem', para a fonte latina sine. Também latinizante parece ser a grafia do vocábulo 'costumauan' na sua terminação em - $n$, que alterna frequentemente com -m e que, em termos gráficos, corresponde melhor do que esta à desinência latina $-n t$ da $3^{\text {a }}$ pessoa do plural das formas verbais.

Um caso de grafia latinizante que envolve elemento nasal e vogais geminadas está também documentado em vários exemplos do extracto acima transcrito. Assim, o substantivo 'corôa' retoma a forma arcaica em que a consoante - $\mathrm{n}$ - do original latino corona conserva os seus vestígios sob a forma de nasalização da vogal antecedente. $\mathrm{O}$ mesmo fenómeno se verifica em 'christáa', derivado do latim christiana; em 'chẽos', proveniente do adjectivo latino plenus; em 'gẽeral', 'origẽe', 'tẽer' e 'tẽe', evoluídos a partir das respectivas formas latinas general (em), origine $(\mathrm{m})$, tenere e tenet.

Fenómeno paralelo a este é o da presença de vogais geminadas que denunciam a consoante latina intervocálica que, por ter esse carácter, ou em associação com ele, teve tendência a sincopar-se na evolução do latim para o português. É o caso dos vocábulos 'veer', 'fee' e 'cijdade', que derivam das respectivas formas latinas uidere, fide $(m)$ e ciuitate $(m)$ e estão bem mais 
próximos da sua matriz histórica, do que nas formas ulteriores reduzidas 'ver', 'fé' e 'cidade', que já existiam no tempo de Resende, mas que ele preteriu em favor da grafia etimológica e latinizante.

No mesmo sentido merece reparo a grafia das formas verbais 'lexe' e 'lexasse', em vez de 'leixe' e 'leixasse' na sua forma vocalizada, já existente desde o séc. XI. Resende optou pela grafia anterior por ela registar um estádio de evolução mais próximo da etimologia do verbo latino laxare; e, como este, também o caso de 'beisa', do verbo 'beisar', em vez de 'beijar' já existente pelo menos desde o séc. XIII, cuja sibilante -s-, em vez de -j-, a coloca foneticamente mais próxima do étimo latino basiare.

Como claro latinismo, pelo menos gráfico, deverá ser considerada a grafia de 'regno' bem como outros daí derivados existentes na mesma "Fala" a que pertence o texto acima transcrito e nas restantes obras resendianas em vernáculo, como nos vocábulos 'regnare' e "regnado", baseados na raiz latina de regnum, em substituição da grafia com a consoante -g- vocalizada ('reyno' ou 'reino'), que já existiam desde o séc. XIII.

No âmbito das consoantes devemos ainda mencionar os dois casos das palavras 'nobleza' e 'plazer', preferidas pelo nosso humanista às formas 'nobreza' e 'prazer', embora antigas, por aquelas manterem a sua raiz mais próxima dos respectivos étimos latinos, a saber, o radical de nobilitas e de placere. E o mesmo se passa com o numeral 'cent', em que Resende retoma a raiz latina de centum, apesar de existirem as formas 
medievais 'çien', 'cem' e outras.

No que respeita ao uso da aspirada h, excluindo os casos da sua presença sistemática na grafia dos artigos definido e indefinido ho, ha, hos, has, e hũo, hũa, que são de tradição antiga e, como se sabe, nada têm que ver com questóes de etimologia, três casos há - 'triumpha', 'catholica' e 'christãa' - em que a sua manutenção aponta evidentemente para a origem latina no primeiro caso e greco-latina nos outros dois.

De notar, ainda, o conjuntivo 'impida', forma arcaica que o autor prefere por conservar mais intacto o radical latino do verbo impedire; bem como o uso da preposição 'per', na sua forma também arcaica e autónoma, isto é, sem se aglutinar nem sequer ao artigo definido ("per hos muros", "per hos coraçôes"), e igualmente preferida por transcrever a exacta forma da sua origem latina.

Quanto ao topónimo 'Hispania', sendo forma assumidamente portuguesa, não deixa de ser um latinismo que aqui designa toda a Península Ibérica. Recordemos que o mesmo André de Resende, em carta de 4 de Maio de 1567, de resposta ao toledano Bartolomeu de Quevedo, lhe lembrava que portugueses e espanhóis eram todos hispanos: "Hispani omnes sumus" (Pereira 1988: 130-131).

Finalmente, para terminar a análise da ortografia latinizante do extracto da "Fala à Princesa Dona Joana", resta-nos referir os vocábulos 'antigua', 'qua' e 'quomo', formas arcaicas de 'antiga', 'ca' e 'como' e cuja grafia mantém o apêndice bilabial -u- da sua etimologia 
latina, que os liga graficamente à sua forma original, respectivamente antiqua, quia e quomodo.

Esta mesma preocupação etimológica mantém-se e abrange muito outro vocabulário na Vida de Frei Pedro como vamos verificar em alguns extractos do seu texto. O primeiro é colhido do início do Proémio, em que frei André de Resende, aos sessenta e cinco anos de vida, recorda seus tempos de noviço do Mosteiro de Sáo Domingos de Évora, onde pôde conhecer de perto as virtudes do porteiro frei Pedro, e explica como assumiu a missão de escrever a sua biografia:

Per algũos padres da ordẽe, persõas religiosas \& doctas, fui per vezes requerido que screnesse ho que sei da virtude $\&$ sanctidade de Frey Pedro porteiro do móesteiro de Sanct Domingos de Euora. Porque, quomo eu en haqlla casa me criey, alcansey tẽer delle hũa particular familiaridade, \& com ipso muita experientia de suas cousas. Prometti de ho fazer, mas dilatey ho muito tempo. [...] Se de este mundo partijsse sen me desobligar de esta diuida, per ventura, \& sen per ventura, tãbẽe me nó desobligaria de dar côpta a d's, por escóder has mercees de q̃ a elle aprouue fazer me participante, \& quiça por ipso hacte ho presente me dar vida, para has publicar. Quero pois cố seu fauor \& adjuda, pagarlhe este deuido tributo [...] (Vd. Vida de Frei Pedro, fol. a iij).

Alguns dos vocábulos aqui destacados estão incluídos no texto anterior e foram objecto do respectivo comentário, por isso trataremos aqui apenas dos restantes.

O adjectivo indefinido 'algũos', com a vogal 
-o- distintiva do masculino, evoca mais de perto a sua formação latina [aliqu(is)+unu(s) > alicunu $>$ aliguno $>$ alguno], do que as formas mais "corruptas" como 'algun/alguns' já existentes no séc. XIII, e constitui, por isso, uma retoma latinizante.

Na palavra 'persóas', Resende prefere e sistematiza a grafia que mantém a líquida -r-do original latino persona, outrora assimilada pela sibilante sequente, e assinala a presença da nasal -n- na forma do til sobre a vogal que a antecede, para efeitos pelo menos da sua nasalização.

Sobre o vocábulo 'doctas', importa lembrar que, embora Duarte Nunes de Leão tenha admitido na Regra II da sua Ortografia, seis anos depois da publicação desta biografia resendiana de Frei Pedro, que a consoante -c- se pronunciava na palavra 'docto' e em outras suas cognatas como 'doctor' e 'doctrina', também presentes nas restantes obras de Resende, em alternância com a grafia da consoante vocalizada 'douto', etc. (LEÂO 1983: 134-135), a verdade é que elas não deixam de ser latinismos.

A mesma consoante da raiz latina é mantida em 'sanctidade' (tal como em 'sancto', 'sancta', 'sanctissima', que aparecem em outros textos resendianos) e na curiosa grafia de 'Sanct' Domingos, que o humanista repete, aproximando-a da forma latina Sanctus até ao limite, isto é, sempre que o nome do santo começa por consoante, por exemplo em 'Sanct' Joanninho, 'Sanct' Paulo, 'Sanct' Mancio e 'Sanct' Pedro, em substituição e paralelismo com a forma portuguesa 'Sam' ou 'São' 
usada em igual circunstância. Isto parece demonstrar que tal grafia não passava de puro grafismo etimológico que nada interferia com a pronúncia de 'Sam' ou 'São', como aliás acontecia muito provavelmente na maior parte dos demais latinismos.

O vocábulo 'screuesse', com ausência do eprotético que, já a partir do latim vulgar, se gerou em palavras começadas pela sibilante s- seguida de uma ou duas consoantes, é mais uma das preferências sistemáticas do programa de relatinização ortográfica de André de Resende, como se vê em muitos outros casos como: scripto e scriptura, scada e scala, scandalizar, scapulario, scasso, scrupulo, scudella, spaço, spelho, sperar, spirito, spiritual, squeecimento, squivo, staca, star (com abundantes exemplos da sua variada morfologia), stilo, stimular, strado, strella, strellado, studioso.

As palavras 'mõesteiro' e 'mercees' são mais dois exemplos de arcaísmos latinizantes, o primeiro porque mantém no til o que resta da nasal-n-de monasterium, e o segundo pela presença da vogal geminada denunciadora da consoante intervocálica original do latim mercedes, entretanto sincopada.

Também testemunha a sua origem latina a palavra 'desobligar' com a líquida originária -1- , como já vimos acima em 'nobleza' e 'plazer', e como acontece com outros casos da obra de Resende, designadamente em 'blando', 'noble' e 'regla'. E o mesmo se diga das formas 'prometti' com sua geminada latina; 'cópta' com o radical latino incorrupto herdado de computare; e muito claramente a grafia de 'experientia', que, à semelhança de outras 
terminadas em -entia, em vez de -ência, ('negligentia', 'patientia') transcrevem simplesmente o latim.

Caso curioso de latinismo gráfico é o pronome 'ipso', como também as formas masculina 'epse' e feminina 'epsa', que resultam do latim ipse, ipsa, ipsum, e percorrem sistematicamente os textos portugueses de Mestre André, constituindo o que se me afigura uma raridade ortográfica.

A forma 'hacte', grafia resendiana da preposição e advérbio 'até', tem dividido os etimologistas entre propostas diferentes, uma árabe (hattā), outra latina ( $a d$ tenus). Não será que André de Resende, ao escrevê-la com aspirada inicial, não teria no pensamento uma outra hipótese, ainda que eventualmente errada, nada menos que o advérbio latino hactenus, que tem valor semântico muito semelhante?

O demonstrativo 'haquella', bem como os cognatos 'haquelle', 'haquillo', muito recorrentes em todos os textos de Resende, mantêm a geminada da sua origem latina (eccu+illa, eccu+ille, eccu+illud); e quanto à aspirada inicial, também aqui o humanista poderia ter feito associação com os pronomes demonstrativos latinos hic, haec, hoc. Não é de estranhar tal hipótese, numa época em que os estudos filológicos não dispunham das conquistas e dos meios que a ciência moderna possui.

Passo a transcrever um último trecho da Vida de Frei Pedro para confirmar alguns casos já comentados e sobretudo para apreciar algumas situaçóes de particular interesse quanto ao método com que o humanista conseguia, por vezes com um mínimo toque de 
ortografia, revestir certos vocábulos de uma roupagem latina. No seguinte extracto, Resende refere as qualidades de Frei Pedro como antigo grumete da marinha, onde este aprendera alguns rudimentos de navegação e do necessário conhecimento da astronomia:

Eu vij star frey Pedro arrimado a hũa columna do claustro, com os oclhos para ho ceo, que staua muy sereno \& strellado, \& chegando me a elle quomo familiar, lhe perguntey que oclhana. Respondeo me. Haa muito tempo que de nocte, per este certo poncto attento para ho norte, per cima da cabeça de haquelle acypreste, \& tenho notado ser falso ho que algũos dizem, que ha strella do Norte é ho polo, \& que non se moue (vd. Vida de Frei Pedro, fol. a viij).

Deste trecho são de notar a grafia de 'vij' com a dupla vogal a evocar a mesma $1^{\text {a }}$ pessoa do singular do pretérito perfeito latino vidi, em que o -d-intervocálico veio a cair durante a evoluçáo para vernáculo; a de 'columna', homógrafa da própria forma latina; as de 'nocte' e 'poncto' com manutenção da consoante -clatina; e os vários casos de consoantes geminadas. Em 'strella' e 'strellado' verifica-se exemplo de contaminação ortográfica das raízes latinas de stella e astrum. Mas o mais curioso deste trecho é a grafia do substantivo 'oclho' e respectiva forma verbal 'oclhaua' (e outras, como 'oreclha'), em que, pela reinclusão da simples consoante -c- da raiz latina de oculus dentro do radical vernáculo 'olh-' dela derivado, e por uma espécie de hipergrafismo ou pleonasmo gráfico, o autor concedeu ao produto assim conseguido um visual mais latinizante. 
O sistema ortográfico de André de Resende foi assumido desde jovem e conservado durante a vida inteira, como se vê pelos primeiros trechos em português que dele nos restam, datados de 1535, a saber, dois registos de baptismo que ele ministrou em Évora nos quais já aparecem os mesmos critérios de escrita, incluindo formas latinizadas como 'baptizei', 'assignei' 'octubro' e expressóes como 'ho doctor' e 'assignei aos dias \& era sobredictos'. E assim persistiu até à beira da morte, ocorrida em Dezembro de 1573, segundo se pode ver no texto do seu Testamento, cuja primeira parte ele ainda redigiu por seu punho e de cujo original restam reproduçóes com fidelidade ortográfica garantida pelos editores. Vejamos um extracto do seu início, onde facilmente se detectam, vários dos latinismos já acima comentados e se comprova a constância caligráfica do Mestre André de Resende:

Em nome da Sanctissima Trindade Padre, e Filho, et Spirito Sancto, tres hypostases, ou pessoas, hũa essencia, hũo Deos, non tres Deoses, cuja fee eu indigno sacerdote sempre tive, tenho, e terei quomo catholico filho da Sancta, et universal Egreja Romana, et en nome da perpetua, et nunqua violada Virgen Sancta Maria [...].

In primis declaro que eu me criei no habito et ordẽe de Sanct Domingos, no móesteiro desta cijdade, et nelle fiz profissam, et trouxe ho habito passante trijnta annos, hacte que frei Hieronymo Padilla mo fez tirar, por eu ser exempto, et star en seruiço del Rei, et de seus hirmãos teendo elle para ipso hũo breve da Sancta Sede apostolica quomo constaraa per hũo instromento que sobre ipso tirei, fecto per Philippe Diaz notario [...] (Leitão Ferreira 1916: 130-131). 
A maior parte das formas aqui sublinhadas já foram objecto de comentário, mas não deixarei de notar as grafias greco-latinizantes de 'hypostases', 'Philippe' e 'Hieronymo', bem como a presença da nasal final -n em 'Virgen', que pode ser motivada pela mesma na radical da forma latina uirgin [de uirgo, uirgin(is)]. Por outro lado, 'exempto' e 'fecto' conservam as marcas latinas nas respectivas consoantes $-\mathrm{p}-\mathrm{e}-\mathrm{c}-$, como acontece com numerosas formas cognatas de um e outro, principalmente do segundo. A grafia de 'nunqua' reflecte a latina nunquam, e a geminada de 'trijnta' adverte para a queda da consoante intervocálica do mesmo numeral latino triginta. De resto, em matéria de numerais, Resende usa sistematicamente formas latinizadas como 'cinquo', 'sex' e 'sexcentos', 'septe', 'octo', 'dezocto', 'cent'.

Um texto de capital importância para o estudo da prática ortográfica de Resende é a Carta que ele escreveu em 16 de Março de 1547 a D. Joáo de Castro, dois anos após a passagem deste por Évora na Primavera de 1545 a despedir-se do rei e a preparar a sua partida para o Oriente na qualidade de governador da Índia, recentemente nomeado.

Resende, que "a epse tempo staua en Viana [do Alentejo]", soube depois que o Governador tinha perguntado por ele com intenção de o levar consigo, o que não pôde acontecer, e por isso lhe manifesta o seu reconhecimento por via epistolar. Dessa carta conservase, felizmente, o texto autógrafo, cuja primeira página se pode ver reproduzida no fim deste estudo, o que 
permite verificar o seu estilo ortográfico redigido por sua própria mão e comprovar tudo o que temos dito sobre esta matéria. Vejamos os seus dois primeiros parágrafos:

Mighel da Arruda, stando V. S. en Cepta, me deu os primeiros motiuos de deseiar seruir V. S. hos quaes eu assi en mi criei $\&$ accrescentei, com ho tempo que me descobrio en quem \& quam bẽe empregaua este deseio, que fiquei para eu poder stimular \& accarretar outrem a ipso, \& ia non poder com razam ser en epsa parte mais que outrem stimulado. Porque isto alcançam haquelles que en qualquer genero de virtudes $\&$ habilidade se fazem signalados, que ha meesma virtude $\&$ habilidade assim quomo hos faz ser cognescidos de todos, assi hos faz de todos hos bóos ser amados. [...] (Veja-se Carta a D. João de Castro, ANTT, Ms. da C. de São Lourenço, IV, fol. 52).

A grafia de 'Mighel' com a aspirada -h- exemplifica a função que na ortografia resendiana ela exercia para assinalar o carácter oclusivo da consoante g- quando seguida de -i- ou -e-, expediente que o humanista repete habitualmente em idênticas situaçóes, v.g. em 'entreghe', 'gherra', 'gherreiros', 'fogheado'. Note-se também a grafia alatinada de "signalados", que outras obras igualmente documentam, por exemplo, em 'signal' e 'signo' (o sino da torre); a ausência de nasalização no pronome 'mi', forma que o autor prefere por ser mais condizente com a origem latina mihi; e ainda, a palavra 'meesma', cujas vogais geminadas evocam a sua origem do latim metipsima, e do mesmo modo a nasal de 'bóos', que denuncia a forma latina bonos. 
Outro dos textos portugueses de André de Resende que tem especial interesse para a análise da sua ortografia é o Sermão que ele pregou no sínodo de Évora em 1 de Fevereiro de 1565 e publicou em Agosto de mesmo ano. Transcrevemos um pequeno excerto em que o pregador dominicano proclama a obrigação que sobre todos os homens impende, mas principalmente sobre os sacerdotes, de imitarem neste mundo as virtudes celestes. Vejamos por esta amostra o interesse e a novidade ortográfica que ele contém:

"Et se a todos, quanto mais aa hierarchia ecclesiastica, que na terra mais representa hakella beatissima ordẽe do ceo. Porque quomo esta ciidade de Deos é hũa s[cilicet] hũa Hierusalem, \& nos mediâte ha fee, scriptos por ciidadãos de'lla, [...] posto que inda ca stemos nos arraualdes d'ella, assi quomo tẽemos ha voz \& appellido por el Rei quomo hos de dentro, assi tẽemos obligaçam de nos côformar \& unir nos costumes \& linguagẽe com hakelles que nas plaças \& castello d'ella ja moram." (Vd. Sermão de 1565, [p. 1]).

De entre as formas latinizantes sublinhadas, e pondo de parte as que já foram comentadas em outros passos, destaco a grafia greco-latina dos nomes técnicos 'hierarchia ecclesiastica' e 'Hierusalem', o conjuntivo arcaico 'stemos', que transcreve a própria grafia latina, e a presença da líquida originária em 'plaças', correspondente à forma latina platea, bem como os vários casos de geminadas, quer vogais, quer sobretudo consoantes.

Mas o caso curioso, e que constitui uma novidade, é o uso do -k- em 'hakella' e 'hakelles'. Trata-se de um 
expediente puramente gráfico para substituir o dígrafo -qu-, talvez para evitar o risco de que o apêndice velar -u-do mesmo dígrafo se pronunciasse nos casos em que ele não tivesse valor fonético ${ }^{4}$. Mas isto nada tem que ver com questóes etimológicas. Resende utiliza-o em mais dezassete casos deste Sermão, não apenas neste tipo de adjectivos ou pronomes demonstrativos incluindo 'hakillo', mas também nos seguintes vocábulos: 'frakeza', 'eskeescidos', 'tokeis', 'kebra', 'haki', 'skerda', e nas expressões 'hacté hakelle' e 'hacté haki'. Mais cinco anos depois, veio a usá-lo por duas vezes na Vida de Frei Pedro, com as palavras 'keente' e 'kebra' (fol. a vij; e fol. a viij $\left.v^{o}\right)$.

Por último, transcrevemos alguns passos da História da antiguidade da cidade Évora, preferindo para o efeito o texto da primeira edição, de 1553, uma vez que a segunda, saída a lume postumamente a 1 de Fevereiro de 1576, apesar de ostentar na folha de rosto a notícia de que ainda tinha sido "emendada pelo mesmo autor", falecido havia mais de seis anos, apresenta uma ortografia irregular, incoerente e em muitos casos fora do critério sempre demonstrado por André de Resende. É verdade que a segunda edição apresenta vários acrescentos ao texto da primeira, os quais poderão constituir a tal operação de emenda do autor nela referida. Mas esse é outro aspecto da crítica textual, que não directamente

${ }^{4}$ Fernão de Oliveira, em 1536 , escrevia a tal respeito no cap. IX da sua Grammatica da lingoagem portuguesa: "Tiramos dantras nossas letras .k. porque sem duuida elle antre nos não faz nada: nem eu nunca vi em escritura de Portugal esta letra .k. escrita." Por isso talvez tenha sido esta uma novidade de André de Resende. 
da ortografia. O confronto das duas ediçóes mostra que o editor da segunda, ou o tipógrafo, ou ambos, nem sempre respeitaram a marca ortográfica de mestre André de Resende.

Posto isto, vamos então ao texto resendiano de 1553 acerca da antiguidade de Évora, cuja transcrição tem o objectivo de demonstrar que aquela marca vinha de longe e se manteve em toda a produção de Mestre André em língua portuguesa. Para isso escolhemos alguns extractos da dedicatória feita ao príncipe $\mathrm{D}$. João, filho de D. João III, que havia nascido naquela mesma cidade áulica:

A ho principe nosso senhor.

Muito alto, \& muito poderoso principe, \& senhor nosso.

Lembrame que beisando eu ha mão a .V. A. en Almeirin, oclhou vossa A. pera o arcebispo de Lisbóa, \& perguntoulhe quem eu era, \& tornando se a mi, me dixe que lhe perdóasse que me non cognescera. [...] Mas cô todo la fica inda ha diuida do seruiço que prometti, por ho qual, per minha meesma bocca stou empegnado. Hora medindo minhas forças, $\&$ considerando que hos homẽes dados aas leteras, com leteras seruẽ a hos Reis \& principes, \& que ho tal seruiço a hos meesmos foi acceptissimo, en isto me determinei. [...] paresceo me bẽe tornar ante vossa .A. com esta historia desta sua cijdade Euora. Que por .V. A. en ella nascer, tẽemos sabido que vossa A. lhe quer bẽe quomo a patria, \& ella a V. A. tẽe quomo patria, \& ella a .V.A. ama quomo a filho, \& en elle se reuee quomo en speclho. (Vd. História da antiguidade da ciidade Evora, 1553, fol. a vo e a ij-ij vo). 
A maioria dos latinismos ou formas latinizantes aqui sublinhadas, e sua motivação, já foram comentadas a propósito de outros textos, mas importa dizer uma palavra sobre outros casos que o não foram, designadamente a forma verbal 'dixe', que assenta no radical latino dix- dos tempos do pretérito do verbo dicere e que se mantém sistematicamente ao longo da obra resendiana, como em 'dixer', 'dixemos', 'dixesse'; o particípio 'empegnado', cujo -g- denuncia a raiz latina pignus (penhor, garantia); a forma 'speclho', que apresenta o mesmo fenómeno de grafia hiperetimológica de 'oclho' e 'oclhar' já comentados; a palavra 'letera' por 'letra', que reintroduz uma consoante do latim 'littera', e o advérbio 'hora', cognato e simplificação concorrente de 'hagora', derivado do sintagma latino hac hora.

Note-se, de passagem, o latinismo sintáctico da expressão 'cijdade Evora', em vez de 'cidade de Évora', que aparece no próprio título do rosto e se repete nesta e em outras obras de Resende e que representa o fenómeno da concordância apositiva, decalcado na sintaxe latina.

Os textos aqui apresentados pretendem apenas dar uma imagem reduzida (porque o espaço mais não permite) do sistema ortográfico da língua portuguesa seguido pelo polígrafo André de Resende na sua produção vernácula, cuja exemplificação exaustiva daria uma relação de largas páginas compactas.

Este vasto caudal de latinismos gráficos ou de arcaismos latinizantes não foi naturalmente criação exclusiva do nosso humanista. Com efeito, por um 
lado, muitas grafias representam recuperaçóes de modelos arcaicos mais ou menos recuados, entretanto ultrapassados pela progressiva evolução do português; e, por outro, as mesmas opçóes ortográficas eram seguidas por muitos autores contemporâneos de Resende. Mas foi ele, talvez como ninguém no seu tempo, que assumiu e praticou com mais largueza, decisão e persistência a ortografia de tendência etimológica.

Além disso, Resende não foi um teorizador, mas antes um etimologista prático que aplicou na sua obra aquilo que pensava ser a melhor ortografia para a língua portuguesa. De facto, das poucas vezes que escreveu sobre esta questão, fê-lo de forma indirecta, como quando, ao anotar para os estudiosos alguns passos mais obscuros do seu poema sobre o mártir São Vicente, padroeiro de Lisboa (Vincentius Levita et Martyr, Lisboa, 1545; Adnotationes, p. 47, nota 44), se refere à língua comum dos Lusitanos, recebida de seu lendário epónimo Luso, dizendo. "E realmente ainda perduram na nossa língua, que é quase latina, muitos vestígios de helenismo" (Et reuera, durant adhuc in nostra lingua, quae paene latina est, multa Graecitatis uestigia).

Acresce ainda que, no comentário acerca da conjugação dos verbos (De uerborum coniugatione commentarius, Lisboa, 1540, fol. $\mathrm{H} \mathrm{v}^{\mathrm{o}}-\mathrm{Hij}$ ), que é a sua única obra de carácter propriamente didáctico, o humanista fala sobre "certos homens, aliás sábios e amigos," com pretensão a cortesãos e muito preocupados com as elegâncias da corte, mas que "Atiram para a maior pobreza a lusitana língua, essa língua dos mais 
amplos recursos sem dúvida, essa pagem seguidora do falar latino e sua servente doméstica" (Lusitanam linguam amplisssimam illa quidem, Latinique sermonis pedisequam familiaremque uernaculam, in magnas angustias detrudunt). E a seguir, falando dos benefícios da importação linguística quando devidamente ponderada como os clássicos sempre fizeram, lamenta os hábitos portugueses e ironiza deste modo:

"Nós, é ao contrário. Fazemos, na verdade, tanto descaso do que é nosso, que até da riqueza da língua fugimos com horror. E ninguém julgue que eu digo estas coisas por estar extremamente apaixonado pela língua portuguesa, à qual eu deixarei de todo morrer, desde que ela se transforme na romana que outrora tivemos." (Nos contra. Adeo enim nos nostri piget, ut etiam ab linguae copia abhorreamus. Nec uero quisquam me haec arbitretur dicere, quod multum Lusitanam linguam deamem, cui per me sane perire licebit, modo in Romanam, quam olim habuimus, mutaretur.).

Portanto, e à parte as possíveis ironias, Resende parece que veria com muito prazer que a sua Lusitânia voltasse a falar a língua do Lácio como nos tempos áureos da romanização. Este sentimento explica-se por ele ser não apenas um dos maiores humanistas do renascimento português, mas também um dos competentes estudiosos da história da antiguidade portuguesa e mesmo ibérica, e um especialista em epigrafia latina. É nessa qualidade que, a propósito da ortografia da própria língua latina, numa carta que servia de dedicatória de uma obra intitulada Antiqua 
Epitaphia dirigida ao cardeal D. Afonso, irmão de D. João III, defendia que a melhor ortografia é a oferecida pela epigrafia, pura e simplesmente porque as pedras não mudam, ao passo que a erosão humana tudo transforma e adultera (Pinho 2006: 162-165).

Mestre André de Resende, profundo conhecedor das línguas antigas que estão na base do português, excelente polígrafo em todos os campos da literatura, exímio orador e devotado especialista da história antiga, estava pois especialmente vocacionado para defender e sobretudo praticar uma escrita portuguesa que preservasse a ortografia na sua mais directa matriz original, o padrão da língua latina. Foi isso que ele fez, assumindo na prática o protagonismo de um movimento etimologista de recondução às fontes.

Mas não foi um caminho fácil. Se muitos autores e teóricos seus contemporâneos alinharam na mesma empresa, outros nem por isso.

Entre as vozes autorizadas que elogiaram o critério ortográfico aplicado na sua produção literária vernácula com base na origem da lingua latina, contase o gramático Pêro de Magalhães de Gândavo, que em 1574 no Diálogo que acompanha as suas Regras, evoca e associa ao nome de Joáo de Barros, o do humanista André de Resende, e onde também ressoa a voz de Camóes: "Pois se quereis ver a lingua de que [a portuguesa] he mais vizinha, \& donde manou, lede a arte da grammatica la lingua Portuguesa que o mesmo Ioam de Barros fez, e o mesmo podeis ver no liuro da antiguidade de Euora de Mestre André de Resende, 
onde claramente se mostra, que cô pouca corrupção deixa de ser Latina.” (Gândavo 1574: fol. D viij).

Mas dois anos depois, o gramático Duarte Nunes de Leão, que na carta-dedicatória da sua Ortografia exprime os mesmos conceitos de Resende quanto à preservação da verdadeira ortografia através da epigrafia (Leão 1983: 44), já na Regra II da mesma obra defende claramente o critério fonético "Porque não consiste a polícia da língua portuguesa em as palavras serem mais conjuntas e parecidas com as latinas"; e logo depois lança a seguinte farpa que parece talhada para o humanista eborense: "Pelo que é nojenta escritura e fora de razão a dos que dizem Princepsa, por Princesa, e epse, por esse, e oclho, por olho, e comptar, por contar, por ser mais conforme ao latim,” etc. (LEÃo, 1983: 133).

Reflexos desta crítica e oposição às propostas radicais da ortografia etimológica e latinizante de André de Resende ainda se verificaram em tempos modernos pela voz da grande filóloga Carolina Michaëlis de Vasconcelos, que, a propósito das anomalias da escrita portuguesa do seu tempo, e da necessidade de uma reforma nacional, escrevia numa das suas liçóes de filologia portuguesa (Michaëlis de Vasconcelos s.d.: 104): "Caturrices como cognoscer por conhecer, quomo por como, oclhos por olhos, hacte por até, haghora por agora, ipso por isso - obras do benemérito antiquário André de Resende! - não vingaram felizmente."

Caturrices e exageros ou náo, a verdade é que a escrita latinizante praticada pelo humanista eborense e por outros escritores do seu tempo (incluindo, embora 
de forma hesitante e híbrida, alguns dos gramáticos que teoricamente a contestavam) perdurou, a partir deles e em grande medida, por cerca de quatrocentos anos até à reforma ortográfica simplificada de 1911, que mesmo assim não simplificou de todo algumas das propostas daquele sistema gráfico de tendência histórica e etimológica, ainda hoje vigentes no traje oficial da ortografia da língua portuguesa. 


\section{BibLIOGRAFia}

Barros, João de (1540), Grammatica da lingua Portuguesa [e] dialogo em louvor da nossa linguagem. Lisboa, Luís Rodrigues.

GÂndavo, Pêro de Magalhães de (1574), Regras que ensinam a maneira de escrever e orthographia da lingua portuguesa, com hum dialogo que adiante se segue em defensam da mesma lingua [...]. Lisboa, Officina de Antonio Gonsaluez.

LeÂo, Duarte Nunes de (1983, Ortografia e origem da lingua portuguesa. Introdução, notas e leitura de Maria Leonor Carvalhão Buescu. Lisboa, Imprensa Nacional - Casa da Moeda.

Leitão Ferreira, Francisco (1916), Notícias da vida de André de Resende. Publicadas, anotadas e aditadas por Anselmo Braamcamp Freire. Lisboa, Arquivo Histórico Português.

Michaëlis de Vasconcelos, Carolina (s.d.), Lições de filologia portuguesa, segundo as prelecçóes feitas aos cursos de 1911/12 e de 1912/13, seguidas das liçôes práticas de português arcaico. Lisboa, Dinalivro.

Silva Neto, Serafim da (1947), A santa vida e religiosa conversação de Frei Pedro, porteiro do Mosteiro de S. Domingos de Évora. Rio de Janeiro, Ediçôes Dois Mundos. 
Oliveira, Fernão de (1536), Grammatica da lingoagem portuguesa. Lisboa, Germáo Galharde.

Pereira, Virgínia Soares (1988), André de Resende, Carta a Bartolomeu de Quevedo. Introdução, texto latino, versão e notas. Coimbra, Centro de Estudos Clássicos e Humanísticos da Universidade de Coimbra.

Pinho, Sebastião Tavares de (2006), Humanismo em Portugal. Estudos I. Lisboa, Imprensa Nacional Casa da Moeda.

Resende, André de (1547). "Carta a D. João de Castro, Lisboa 16 de Março de 1547”, ANTT, Manuscritos da C. de S. Lourenço, IV, p. 52-53. 


\section{ANEXo II \\ Primeira página da Fala de André de Resende à PRINCESA D. JOANA}

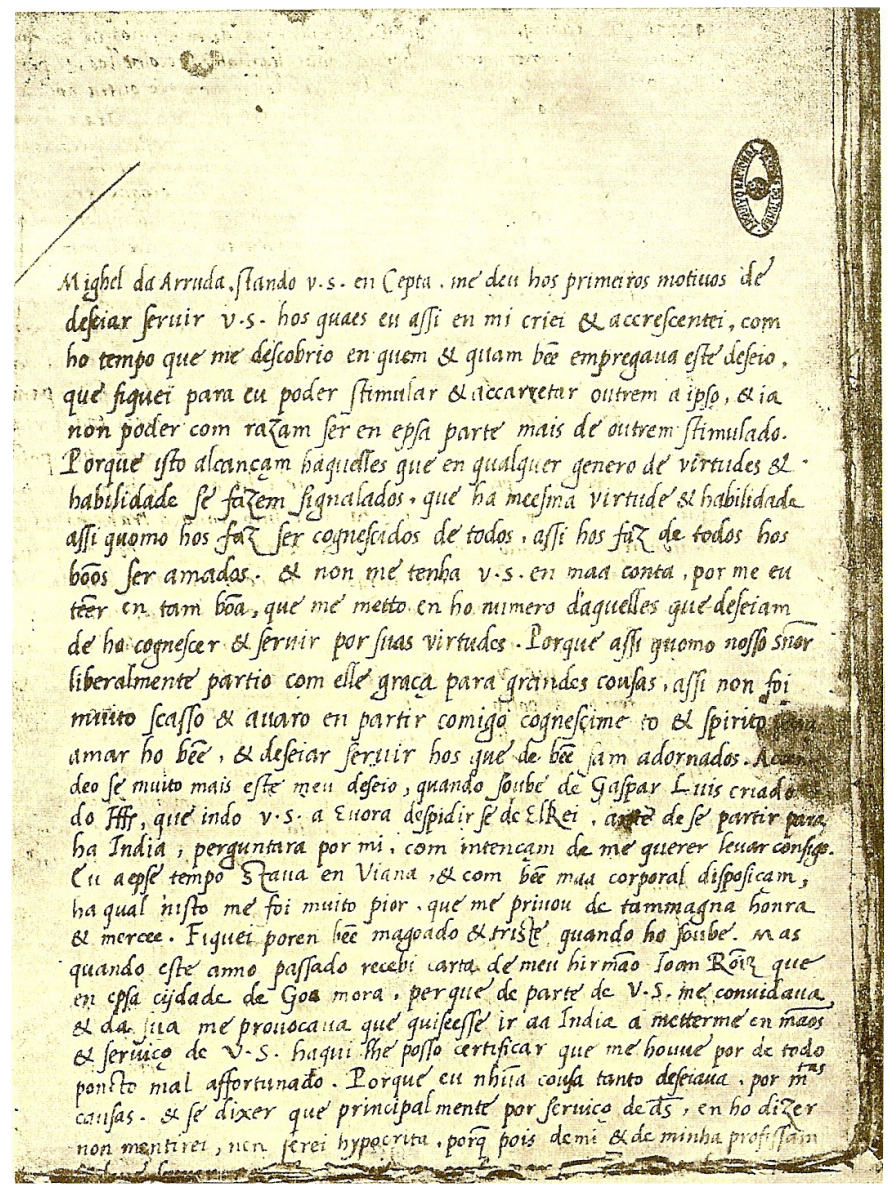




\section{$38 \delta^{2}$

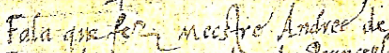

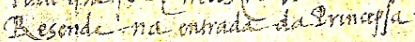

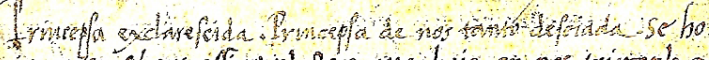

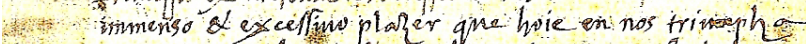
pér pal auras fe podeffe explicar, mus ponco ferna fo qua

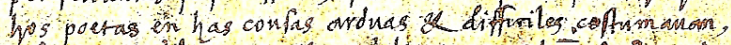

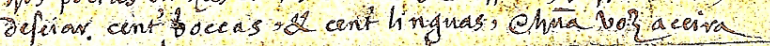

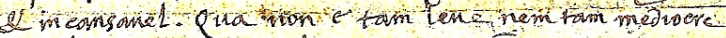

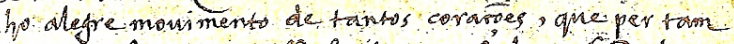
poncos informmentog affi faehmente fe lex alfebedaras.

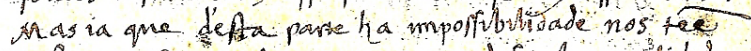
Defengamad, 2 de on no nodere ha gralidale 00 tempo ans com longa orarar detenta a V:A.

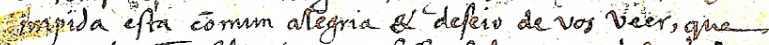

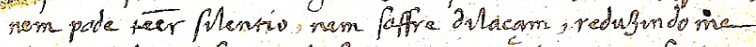

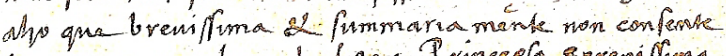
ha nam gre lege de dizer, Prinespla geremifima,

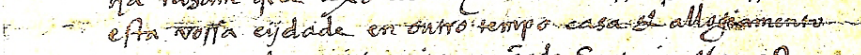

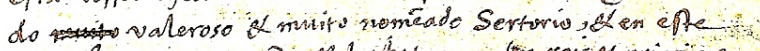

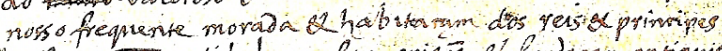

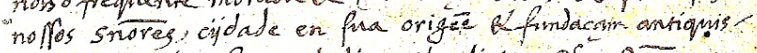
sima, of en tia fue eathalica of religiom Chroftar sware todas has de fifpania on mais antigna, on tanto quan.

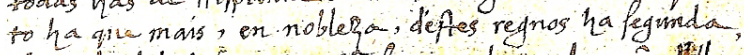

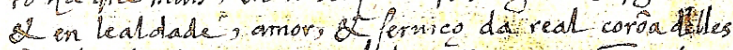
fen dumida ha primersa, beja vorpas reaes más, al pare qus publice al geral vorn com hos anmos cheos de.

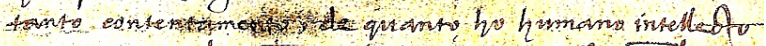

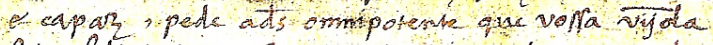
feia felieigrima. Entrou snora per los mines ofos

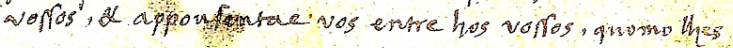

